\title{
Rainfall estimation from in situ soil moisture observations at several sites in Europe: an evaluation of the SM2RAIN algorithm
}

\author{
Luca Brocca $^{1 *}$, Christian Massari $^{1}$, Luca Ciabatta ${ }^{1}$, Tommaso Moramarco ${ }^{1}$, Daniele Penna ${ }^{2}$, \\ Giulia Zuecco ${ }^{3}$, Luisa Pianezzola ${ }^{3}$, Marco Borga ${ }^{3}$, Patrick Matgen ${ }^{4}$, José Martínez-Fernández $^{5}$ \\ ${ }^{1}$ Research Institute for Geo-Hydrological Protection, National Research Council, Perugia, Via Madonna Alta 126, 06128 Perugia, Italy. \\ ${ }^{2}$ Faculty of Science and Technology, Free University of Bozen-Bolzano, Piazza dell'Università 5, Bolzano, Italy. \\ ${ }^{3}$ Department of Land and Agroforest Environments, University of Padova, Via dell'Università 16, Legnaro, Italy. \\ ${ }^{4}$ Luxembourg Institute of Science and Technology (LIST), ERIN, Avenue Des Hauts-Fourneaux 5, Esch-Sur-Alzette, Luxembourg. \\ ${ }^{5}$ Centro Hispano Luso de Investigaciones Agrarias, USAL, Calle del Duero 12, Villamayor, Spain. \\ * Corresponding author. Tel.: +39 0755014418. Fax:+39 0755014420. E-mail: luca.brocca@irpi.cnr.it
}

\begin{abstract}
Rain gauges, weather radars, satellite sensors and modelled data from weather centres are used operationally for estimating the spatial-temporal variability of rainfall. However, the associated uncertainties can be very high, especially in poorly equipped regions of the world. Very recently, an innovative method, named SM2RAIN, that uses soil moisture observations to infer rainfall, has been proposed by Brocca et al. (2013) with very promising results when applied with in situ and satellite-derived data. However, a thorough analysis of the physical consistency of the SM2RAIN algorithm has not been carried out yet. In this study, synthetic soil moisture data generated from a physically-based soil water balance model are employed to check the reliability of the assumptions made in the SM2RAIN algorithm. Next, high quality and multiyear in situ soil moisture observations, at different depths $(5-30 \mathrm{~cm})$, and rainfall for ten sites across Europe are used for testing the performance of the algorithm, its limitations and applicability range.

SM2RAIN shows very high accuracy in the synthetic experiments with a correlation coefficient, $\mathrm{R}$, between synthetically generated and simulated data, at daily time step, higher than 0.940 and an average Bias lower than $4 \%$. When real datasets are used, the agreement between observed and simulated daily rainfall is slightly lower with average R-values equal to 0.87 and 0.85 in the calibration and validation periods, respectively. Overall, the performance is found to be better in humid temperate climates and for sensors installed vertically. Interestingly, algorithms of different complexity in the reproduction of the underlying hydrological processes provide similar results. The average contribution of surface runoff and evapotranspiration components amounts to less than $4 \%$ of the total rainfall, while the soil moisture variations $(63 \%)$ and subsurface drainage $(30 \%)$ terms provide a much higher contribution. Overall, the SM2RAIN algorithm is found to perform well both in the synthetic and real data experiments, thus offering a new and independent source of data for improving rainfall estimation, and consequently enhancing hydrological, meteorological and climatic studies.
\end{abstract}

Keywords: Rainfall; Soil moisture; In situ observations; Experimental sites; SM2RAIN.

\section{INTRODUCTION}

Rainfall is the most important input variable for many applications in hydrology, geomorphology, climatology, and agronomy. For instance, rainfall has to be accurately quantified for flood prediction at the catchment scale (Brocca et al., 2013; Kirchner, 2009), for the assessment of landslide susceptibility (e.g., Brocca et al., 2012; Hong et al., 2007), or for the prediction of crop yield (Ramarohetra et al., 2013). Therefore, the knowledge of rainfall is essential for mitigation strategies of natural hazards (Wake, 2013), as well as for disease and famine prevention (Hou et al., 2014).

The most common ground-based method for estimating rainfall relies on rain gauge observations that are known to be prone to spatial representativeness issues (Kidd et al., 2014). In this respect, weather radars can be used to overcome the spatial coverage problem of rain gauges by providing rainfall estimates over large areas with high spatial and temporal resolutions (Villarini and Krajewski, 2010). However, weather radars measure rainfall indirectly and, therefore, might be affected by large uncertainties (Borga, 2002). In recent years, remote sensing sensors are increasingly employed in many parts of the world, mainly in poorly gauged areas, for estimating rainfall through different algorithms and sensor types (Hou et al., 2014). Despite this, satellite rainfall products often fail in reproducing the rainfall patterns because of the indirect nature of satellitebased observations (Kucera et al., 2013). An alternative source for rainfall estimation is provided by short-range forecasts from numerical weather prediction models (Ebert et al., 2007) that, however, suffers from the known limitations of modelled data (e.g., model structure, parameterization, input data). Therefore, the estimation of rainfall with good accuracy is still an open issue and the use of new methodologies or observation types can be highly beneficial (Tuttle and Salvucci, 2014).

In the last few years, some attempts have been made for using discharge (Kirchner, 2009; Krier et al., 2012) and soil moisture (e.g., Brocca et al., 2014a; Chen et al., 2012; Pellarin et al., 2013) observations for correcting or for estimating rainfall. More specifically, some authors (Crow et al., 2009, 2011; Pellarin et al., 2013) integrated satellite soil moisture observations with land surface modelling in a data assimilation framework. The differences between observed and simulated data through the land surface model are used to correct the input rainfall data. A different approach was recently proposed by Brocca et al. (2013) who used soil moisture data to obtain a direct quantitative estimate of rainfall. By doing "hydrology backward" (as suggested by Kirchner, 2009), rainfall is computed from the knowledge of soil moisture state and its variation in time through an algorithm called SM2RAIN. A similar approach was also proposed by Tian et al. (2014) for estimating 
snowfall from snow water equivalent observations obtained by passive microwave satellite sensors.

SM2RAIN has been applied to in situ (Brocca et al., 2013) and satellite (Brocca et al., 2014a, 2014c; Ciabatta et al., 2015) observations with successful results at the regional (Italy and Australia) and global scale. Moreover, the rainfall estimates obtained from SM2RAIN have also been considered for the correction of observed rainfall data obtained from rain gauge. In particular, Massari et al. (2014), in a small catchment in southern France, found that the corrected rainfall provides improvement in flood modelling when compared to the use of rain gauge observations only. These results are promising, but a detailed study investigating the physical basis of the SM2RAIN algorithm, its range of applicability and its limitations is needed. Indeed, for sake of simplicity, in the first applications of the SM2RAIN algorithm it is assumed that the contribution of evapotranspiration and surface runoff are negligible during rainfall. The validity of these assumptions has still to be addressed.

On this basis, the main objective of this study is to investigate the physical basis of the SM2RAIN algorithm formulation and its performance over a range of climates and locations in Europe. For this purpose, ten sites across Europe are selected for which high-quality (i.e., good accuracy and fine temporal resolution) in situ observations of rainfall, soil moisture and air temperature are available. For each site, different formulations of the SM2RAIN algorithm are used and compared to assess the differences in terms of performance and physical consistency. Besides real observations, synthetic data derived from the application of the physically-based soil water balance model developed by Brocca et al. (2014b) are considered. This allows us to test more in depth the trustworthiness of the assumptions made in the SM2RAIN algorithm.

\section{SOIL MOISTURE AND RAINFALL DATASETS}

Rainfall, soil moisture and air temperature data from ten sites across Europe are used: Petrelle (hereinafter named as PET) and Ingegneria (ING) in central Italy (Brocca et al., 2014b), Bagnoli (BAG), Salento (SAL), and Torano (TOR) in southern Italy (Brocca et al., 2011; Dorigo et al., 2011), Ressi (RES) in northern Italy (Penna et al., 2014), Bibeschbach (BIB) in Luxembourg (Matgen et al., 2012), K10 and M09 stations of the Remedhus network in Spain (Martinez-Fernandez and Ceballos, 2005) and Valescure (VAL) in France (Tramblay et al., 2010). The main characteristics of each site are reported in Table 1 while Figure 1 shows the location of the test sites. The climatic properties of the sites range between humid temperate (northern Italy, France and Luxembourg) and semiarid (Southern Italy

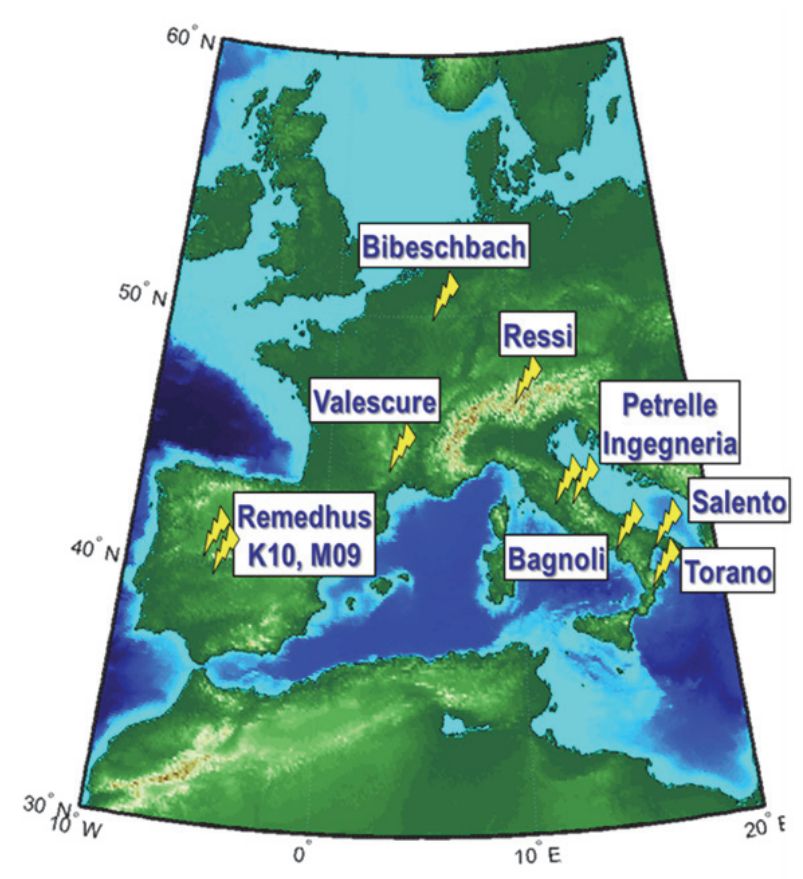

Fig. 1. Location of test sites with hourly observations of rainfall, air temperature, and soil moisture.

and Spain). At each site, hourly-based observations are available for at least two consecutive years. Volumetric soil moisture measurements were taken at different depths (Table 1) through continuous monitoring sensors based on Frequency and Time Domain Reflectometry (FDR and TDR) techniques.

\section{METHODS \\ SM2RAIN algorithm}

The SM2RAIN algorithm is based on the inversion of the soil water balance equation for retrieving rainfall from soil moisture data. The soil is assumed to work as a natural rain gauge for measuring the amount of rainfall fallen into the ground. Specifically, the soil water balance equation can be described by the following expression (Figure 2):

$$
n Z d s(t) / d t=p(t)-g(t)-r(t)-e(t)
$$

where $n[-]$ is the soil porosity, $Z[\mathrm{~L}]$ is the soil layer depth, $s(t)[-]$ is the relative saturation of the soil or relative soil

Table 1. Main characteristics of the selected test sites.

\begin{tabular}{lcccccc}
\hline$\#$ & Site ID & Location & Country & Data period & $\begin{array}{c}\text { Soil moisture sampling } \\
\text { depth [cm] }\end{array}$ & Climate \\
\hline 1 & BAG & Bagnoli & Southern Italy & $2007-2008$ & $25-35$ & Semiarid \\
2 & BIB & Bibeschbach & Luxembourg & $2007-2008$ & $4-7$ & Humid temperate \\
3 & ING & Ingegneria & Central Italy & $2009-2012$ & $2.5-7.5$ & Sub-humid \\
4 & K10 & Remedhus-K10 & Spain & $2007-2009$ & $2.5-7.5$ & Semiarid \\
5 & M09 & Remedhus-M09 & Spain & $2008-2012$ & $2.5-7.5$ & Semiarid \\
6 & PET & Petrelle & Central Italy & $2010-2014$ & $5-15$ & Sub-humid \\
7 & RES & Ressi & Northern Italy & $2012-2014$ & $0-30$ & Humid temperate \\
8 & SAL & Salento & Southern Italy & $2010-2014$ & $15-25$ & Semiarid \\
9 & TOR & Torano & Southern Italy & $2007-2010$ & $25-35$ & Semiarid \\
10 & VAL & Valescure & France & $2008-2010$ & $25-35$ & Humid temperate \\
\hline
\end{tabular}




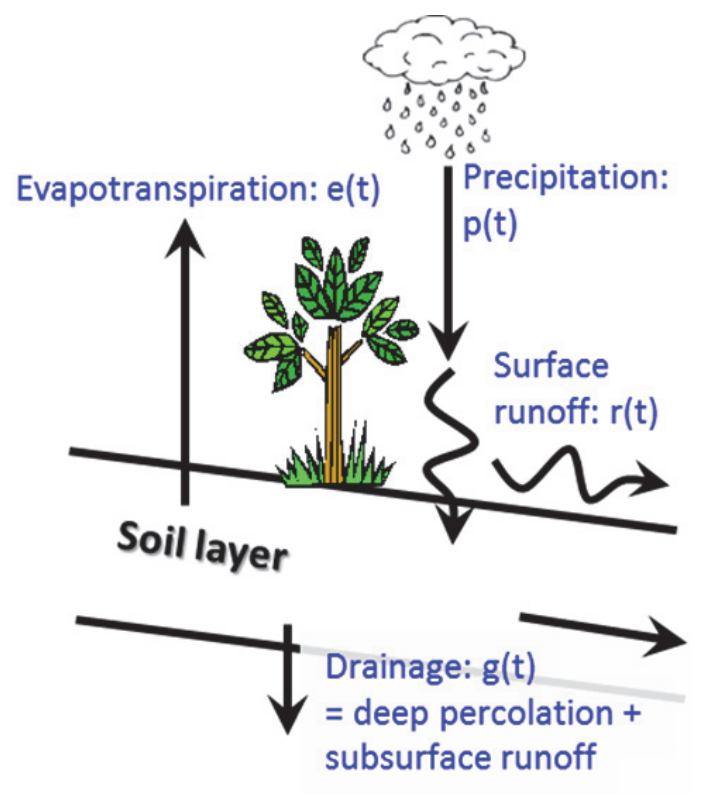

Fig. 2. Schematic representation of the soil water balance equation and fluxes used in the SM2RAIN algorithm.

moisture, $t[\mathrm{~T}]$ is the time and $p(t), r(t), e(t)$ and $g(t)[\mathrm{L} / \mathrm{T}]$ are the precipitation, surface runoff, evapotranspiration and drainage (deep percolation plus subsurface runoff) rate, respectively. For sake of simplicity, the interception rate is not considered here, as it would need the use of another expression for simulating the water content of the interception storage. For the drainage rate, the following relation is adopted (Famiglietti and Wood, 1994):

$$
g(t)=a s(t)^{b}
$$

where $a[\mathrm{~L} / \mathrm{T}]$ and $b[-]$ are two parameters expressing the nonlinearity between drainage rate and soil saturation. Note that $g(t)$ includes the contribution of deep percolation and subsurface runoff (interflow plus baseflow). Basically, $g(t)$ represents the lateral and downward losses of water from the soil column (see Figure 2). The surface runoff rate is expressed in accordance with Georgakakos and Baumer (1996):

$$
r(t)=p(t) s(t)^{c}
$$

where $c[-]$ is a parameter which assumes values greater than unity, with large values representing a highly nonlinear threshold behaviour. The evapotranspiration rate is represented by a linear relation depending on the potential evapotranspiration, $E T_{\text {pot }}(t)$ (e.g., Brocca et al., 2014b):

$$
e(t)=E T_{\text {pot }}(t) s(t)
$$

The potential evapotranspiration is computed through the empirical relation of Blaney and Criddle as modified by Doorenbos and Pruitt (1977):

$$
E T_{\text {pot }}(t)=-2+1.26\left[\xi\left(0.46 T_{a}(t)+8.13\right)\right]
$$

where $T_{a}(t)\left[{ }^{\circ} \mathrm{C}\right]$ is the air temperature and $\xi[-]$ is the percentage of total daytime hours for the period used (daily or monthly) out of total daytime hours of the year $(365 \times 12)$. The rearrangement of Equation (1), by integrating Equations (2-4), yields:

$$
p(t)=\frac{Z^{*} d s(t) / d t+a s(t)^{b}+E T_{p o t}(t) s(t)}{1-s(t)^{c}}
$$

where $Z^{*}=Z n[\mathrm{~L}]$ represents the water capacity of the soil layer. This equation can be used for estimating the precipitation rate, $p(t)$, once the relative soil moisture, $s(t)$, the four parameters $\left(Z^{*}, a, b\right.$, and $\left.c\right)$ and the potential evapotranspiration rate, $E T_{\text {pot }}(t)$, are known. Negative rainfall values, that might occur during some dry-down cycles, are set equal to zero.

We note that the use of Equation (6) for estimating rainfall has some limitations that occurs when the soil is saturated, for highly permeable soils, during snow and frozen conditions and for densely vegetated areas. Some of these issues are discussed in the text.

\section{SM2RAIN algorithm simplifications}

In previous studies, a simplified version of the SM2RAIN algorithm was considered (Brocca et al., 2013, 2014a) by neglecting the contributions of surface runoff and evapotranspiration. With the purpose of quantifying the contribution of each term of Equation (6) to the total rainfall estimation and to its performance, three further algorithm simplifications are introduced:

$$
p(t)=\frac{Z^{*} d s(t) / d t+a s(t)^{b}}{1-s(t)^{c}} \text { neglecting } \mathrm{e}(t)
$$

$$
\begin{array}{r}
p(t)=Z^{*} d s(t) / d t+a s(t)^{b}+E T_{\text {pot }}(t) s(t) \\
\text { neglecting } r(t)
\end{array}
$$

$$
\begin{aligned}
p(t)=Z^{*} d s(t) / d t+a s(t)^{b} & \\
& \text { neglecting both } r(t) \text { and } e(t)
\end{aligned}
$$

We note that Equation (9) is the expression used in previous studies (Brocca et al., 2013, 2014a; Massari et al., 2014). It is characterized by the lowest number of parameters to be estimated (three). Therefore, four algorithm versions of SM2RAIN are tested in this study with decreasing complexity. Firstly, the parameters of the complete model (Eq. 6) are calibrated for reproducing observed rainfall data. Secondly, the three simplified expressions (Equations 7-9) are used. Note that the parameters associated to Equations (7-9) are re-calibrated allowing to obtain the maximum performance for each configuration.

\section{Set up of the synthetic experiments}

The physically-based soil water balance model developed by Brocca et al. (2014b) is employed for producing synthetic soil moisture data. The model uses the semi-analytical relationship proposed by Corradini et al. (1997) for simulating the soil moisture temporal evolution at the soil surface and for the soil profile. The model is found to be accurate, with respect to the exact solution given by the Richard's equation, even for very complex rainfall events characterized by a sequence of infiltrationredistribution cycles. The model evaluation with in situ and laboratory observations (Brocca et al., 2014b; Melone et al., 2008; Morbidelli et al., 2011) confirms its reliability in reproducing the temporal evolution of soil moisture. 
The synthetic experiments are built as follows. Rainfall and temperature data from three representative sites, according to climatic conditions and measurement depth, are considered (i.e., ING, K10, and VAL). These data are used as input into the soil water balance model for simulating the hourly soil moisture temporal evolution from the surface to the depth of the corresponding in situ observations (e.g., from 0 to $5 \mathrm{~cm}$ for the ING site). The parameter values used in the simulations are obtained from a previous model application at the same sites (Brocca et al., 2014b). Then, the simulated soil moisture data are used as input into the SM2RAIN algorithm and the estimated rainfall, obtained by minimizing the root mean square error, RMSE, between observed and simulated data, is compared in turn with the observed rainfall data. In this way, it is guaranteed that rainfall and soil moisture observations are not affected by measurement errors. Assuming that the employed soil water balance model is able to properly reproduce the physical processes involved in the simulation of soil moisture, the error is only due to the assumptions made in the SM2RAIN algorithm (e.g., neglecting surface runoff). Therefore, synthetic experiments represent a robust test for the physical consistency of the SM2RAIN algorithm.

\section{Performance score}

The assessment of the performance of the SM2RAIN algorithm is carried out by considering three different scores: the correlation coefficient, R; the Bias, defined as the mean difference between simulated and observed rainfall; and the fractional root mean square error, fRMSE, that is the ratio between the root mean square error, RMSE, and the standard deviation of the observed rainfall time series. The fRMSE is self-contained, and has a well-defined range between 0 (perfect estimates) and 1 (noise, with no signal of the truth) (Draper et al., 2013). We note that fRMSE values greater than $1 / \sqrt{2}=0.707$ imply an error variance that exceeds the variance of the true time series (see Draper et al. (2013) for details). Therefore, fRMSE lower than 0.707 indicates satisfactory model performance. For all algorithm formulations, the minimization of the fRMSE is considered as objective function while a gradient-based approach is adopted as optimization algorithm. All the results are analysed at a daily time scale, i.e. the capability of SM2RAIN to estimate the daily-cumulated rainfall is assessed. A daily time step is chosen because previous studies (Brocca et al., 2013; Massari et al., 2014) showed that SM2RAIN is able to reproduce rainfall with a time step from four to six times larger than the one of the input soil moisture data (e.g., if hourly soil moisture data are used, good results for 6-hour accumulated rainfall estimates are obtained).

\section{RESULTS AND DISCUSSIONS}

As mentioned above, the different formulations of SM2RAIN are tested by firstly considering the synthetic experiments. Secondly, the real data are analysed by splitting the dataset in a calibration and a validation period. The algorithm performance and the parameter values for each site are analysed, also as a function of climate and sensor depth. Moreover, the contribution of each component of Equation (6) is investigated for quantifying their significance in the determination of the total rainfall.

\section{Synthetic experiments}

For the synthetic experiments, three sites are selected, i.e., ING, K10, and VAL, and the corresponding rainfall and air temperature data are used as input into the soil water balance model. From the inversion of the simulated soil moisture data through the SM2RAIN algorithm, rainfall is estimated and compared against observed rainfall at a daily aggregation step. Figure 3 shows the comparison of daily rainfall data for the K10 and VAL sites along with the simulated soil moisture time series through the complete version of the SM2RAIN algorithm (Equation 6). As it can be seen, the simple analytical equation proposed here is able to reproduce the observed rainfall data with very high accuracy. In terms of performance scores (Table 2), the R-values for the three sites range between 0.922 and 0.957 and the fRMSE values range between 0.289 and 0.388 . A mean value of fRMSE equals to 0.337 indicates a very high performance of SM2RAIN as it is much lower than the fRMSE threshold value $(=0.707)$ below which a model is assumed to properly reproduce observations (Draper et al., 2013). Successively, all versions of the SM2RAIN algorithm (Equations 7-9) are applied to the synthetic soil moisture data; Table 2 summarizes the model performance for all cases. The results clearly show that the model performances are very similar for the different formulations (mean R-values ranging between 0.940 and 0.944 ) with differences in the scores being lower than 3\%. It should be underlined that SM2RAIN is also able to reproduce accurately the total amount of rainfall with average Bias values always lower than $4 \%$. Surprisingly, even though not significantly different from the other formulations, better performance is obtained by using Equation (7) which incorporates only the surface runoff component and not the evapotranspiration. This unexpected result might be due to the indirect incorporation of the evapotranspiration losses in the drainage term. Therefore, the addition of the evapotranspiration term provides a deterioration of the model performance. However, further analyses are required to clarify this aspect.

Table 2. Performance of the different formulations of the SM2RAIN algorithm in the synthetic experiments (R: correlation coefficient, fRMSE: fractional root mean square error). The highest R-values are highlighted in bold.

\begin{tabular}{|c|c|c|c|c|c|c|c|c|c|c|c|c|}
\hline \multirow[b]{2}{*}{ Site ID } & \multicolumn{3}{|c|}{ Eq. (6) } & \multicolumn{3}{|c|}{ Eq. (7) } & \multicolumn{3}{|c|}{ Eq. (8) } & \multicolumn{3}{|c|}{ Eq. (9). } \\
\hline & $\begin{array}{c}\mathrm{R} \\
{[-]}\end{array}$ & $\begin{array}{c}\text { fRMSE } \\
{[-]}\end{array}$ & $\begin{array}{l}\text { Bias } \\
{[\%]}\end{array}$ & $\begin{array}{c}\mathrm{R} \\
{[-]}\end{array}$ & $\begin{array}{c}\text { fRMSE } \\
{[-]}\end{array}$ & $\begin{array}{l}\text { Bias } \\
{[\%]}\end{array}$ & $\begin{array}{c}\mathrm{R} \\
{[-]}\end{array}$ & $\begin{array}{c}\text { fRMSE } \\
{[-]}\end{array}$ & $\begin{array}{l}\text { Bias } \\
{[\%]}\end{array}$ & $\begin{array}{c}\mathrm{R} \\
{[-]}\end{array}$ & $\begin{array}{c}\text { fRMSE } \\
{[-]}\end{array}$ & $\begin{array}{l}\text { Bias } \\
{[\%]}\end{array}$ \\
\hline $\mathrm{ING}^{*}$ & 0.942 & 0.335 & 8 & 0.949 & 0.315 & 3 & 0.942 & 0.336 & 6 & 0.945 & 0.327 & 3 \\
\hline $\mathrm{K} 10^{*}$ & 0.922 & 0.388 & 2 & 0.926 & 0.377 & -1 & 0.923 & 0.384 & 1 & 0.925 & 0.379 & -1 \\
\hline VAL* & 0.957 & 0.289 & 3 & 0.958 & 0.287 & 1 & 0.955 & 0.297 & 4 & 0.955 & 0.296 & 2 \\
\hline Av. & 0.940 & 0.337 & 4 & 0.944 & 0.326 & 1 & 0.940 & 0.339 & 4 & 0.942 & 0.334 & 1 \\
\hline
\end{tabular}

* Synthetic data generated by using the observed rainfall and temperature data at the corresponding sites. 

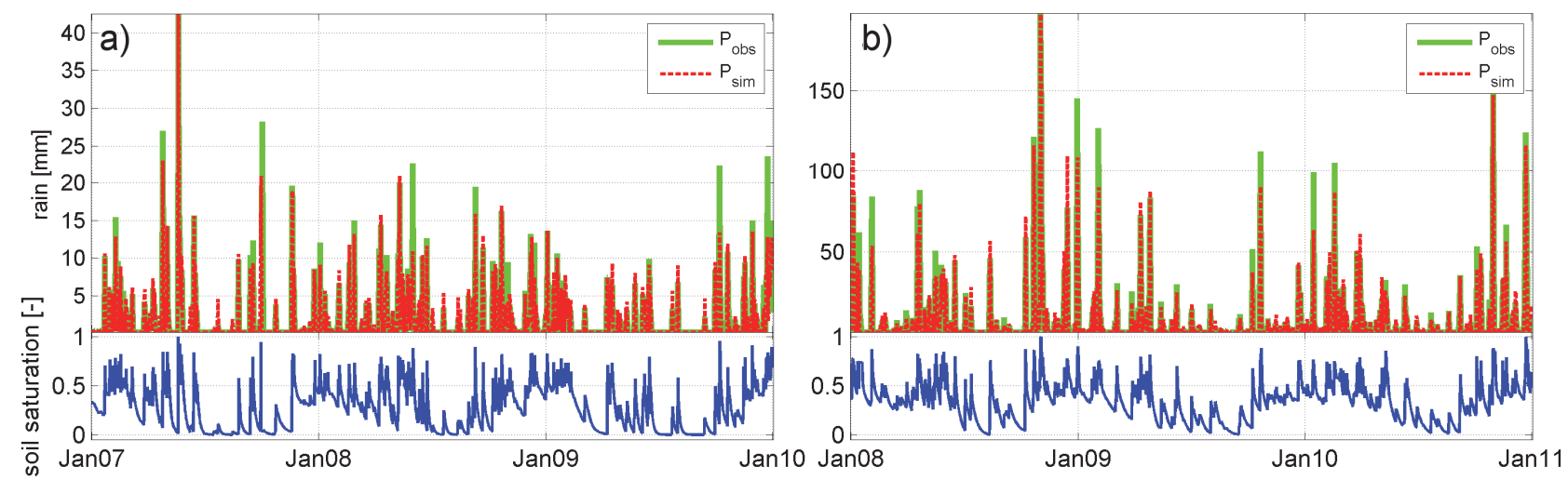

Fig. 3. Comparison between the observed and simulated, through Equation (6), daily rainfall time series (upper panels) and soil moisture data (lower panels) for the synthetic experiment with K10 (a) and VAL (b) dataset as input.
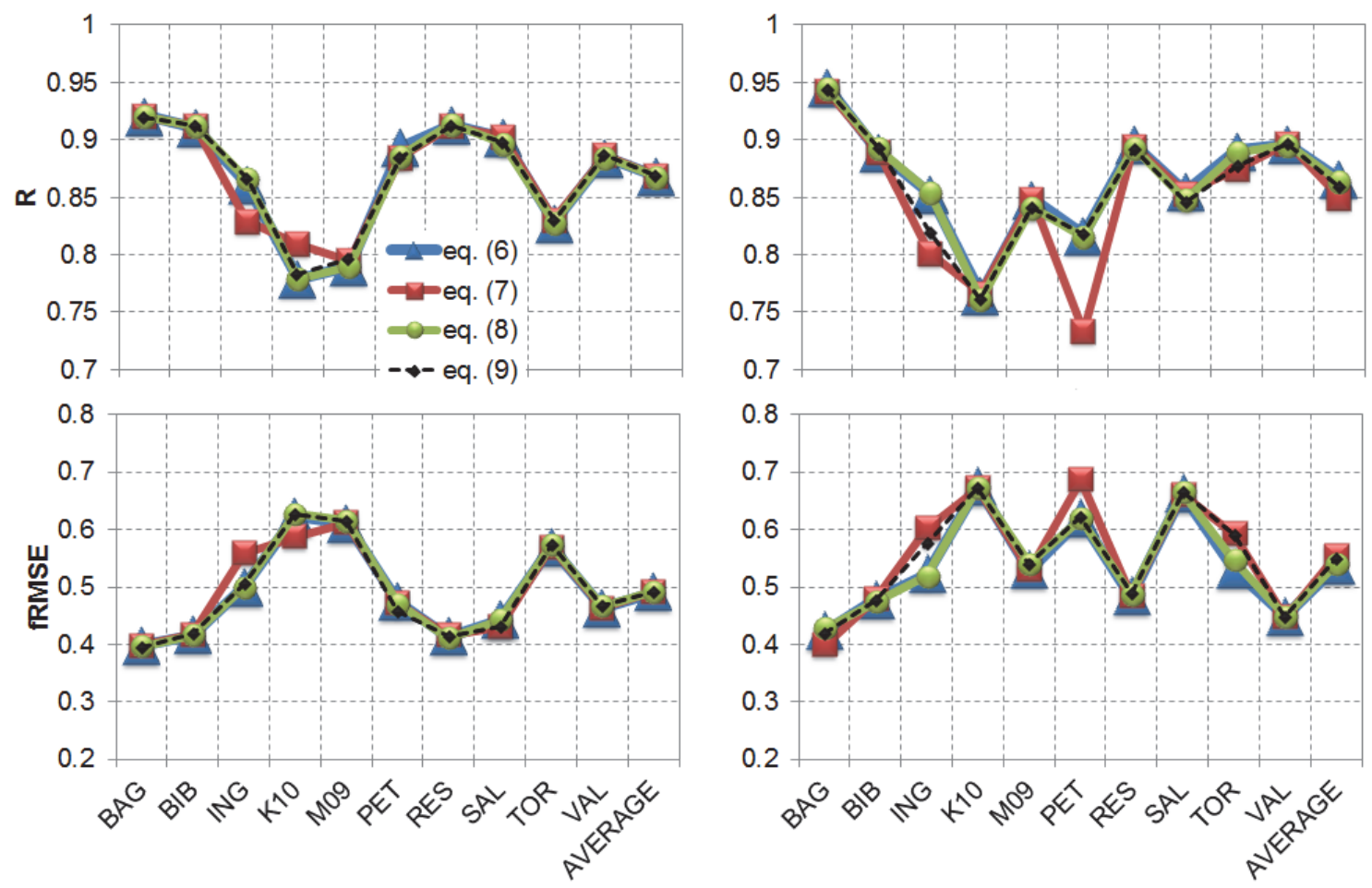

Fig. 4. Performance of the different formulations of the SM2RAIN algorithm in the calibration (left) and validation (right) period for the real data experiment (R: correlation coefficient, fRMSE: fractional root mean square error).

Finally, by comparing the results of the three sites, the highest performance of all configurations is obtained for the VAL site and the lowest for the K10 site, thereby indicating that SM2RAIN seems to perform better in humid temperate climates. This can be ascribed to the less pronounced variations of soil moisture data in humid temperate climate that allow us to obtain better results when the data are inverted through the SM2RAIN algorithm.

\section{Real data experiments}

For the ten selected sites, the parameter values of the complete version of the SM2RAIN algorithm (Equation 6) are calibrated in the first half of the period (that is different for each site). Next, the model is applied with the calibrated parameter values to the second half of the period. The performance in the two periods in terms of $\mathrm{R}$ and fRMSE are summarized in Figure 4.
The agreement between observed and estimated daily rainfall data is quite satisfactory with an average R equal to 0.87 (0.87) and an fRMSE equal to $0.49(0.54)$ in the calibration (validation) period. However, the model was found to underestimate the total rainfall amount at all sites except for ING, where the Bias (not shown for brevity) ranges between $-23 \%$ to $-8 \%$ (excluding ING) with an average value of $-15 \%$. Moreover, also the temporal variability of the estimated rainfall is slightly underestimated with an average difference of $-12 \%$ between the estimated and observed standard deviation. This could be ascribed to the well-known issue occurring at saturation in all the methodologies based on soil moisture data for estimating or correcting rainfall (Brocca et al., 2013; Chen et al., 2014). Indeed, at saturation the soil moisture value remains at a constant level for any rainfall amount; i.e. soil moisture measurement cannot provide useful information for rainfall estimation. Based on these considerations, it is expected that soil moisture-based 

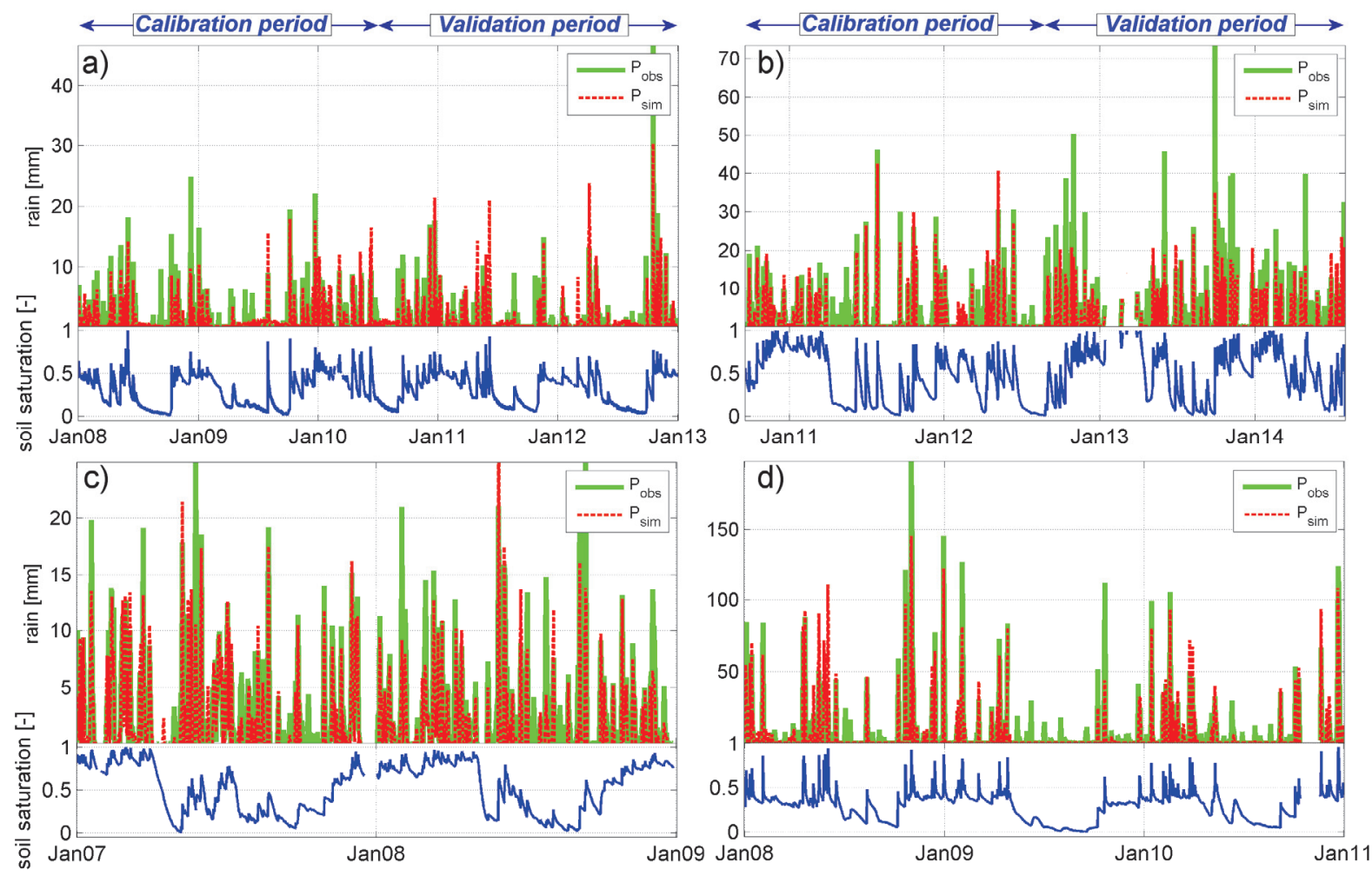

Fig. 5. Comparison between the observed and simulated, through Equation (6), daily rainfall time series (upper panels) and soil moisture data (lower panels) for the real data experiment in the calibration and validation periods at: a) M09, b) PET, c) BIB, and d) VAL sites. Missing data for PET site in January-March 2013 is due to malfunctioning of the soil moisture sensor.

methods will provide an underestimation of the total rainfall (Crow et al., 2011). For the same issue, an underestimation of large rainfall intensities is also obtained (Figure 5).

Figure 5 shows the observed and simulated rainfall for four representative (again according to their climate and measurement depth) sites: M09, PET, BIB, and VAL. The issue occurring at saturation is evident for the PET site (Figure $5 \mathrm{~b}$ ) in the second half of 2012 and in the period from October 2013 to January 2014 where the model consistently underestimates rainfall. However, in January 2011 the same issue is not observed likely due to lower rainfall intensities. Therefore, underestimation is found when saturated soil conditions and high rainfall intensities occur. Another issue is observed in the summer periods, especially for semiarid climates and for sensors located close to the soil surface, for which soil moisture patterns are noisy due to the influence of air temperature on the measured signal. For instance, in Figure 5a it is evident that at the M09 site (sensor depth of $5 \mathrm{~cm}$ ) artificial rainfall is estimated from SM2RAIN during summer with no corresponding observed rainfall. Moreover, for sensors installed horizontally at locations deeper than $\sim 20 \mathrm{~cm}$, it might occur that no soil moisture variations are observed after a rainfall event as the water does not infiltrate down to the depth of the sensor. This issue is observed at the VAL site in the summer of 2009 and 2010 (see Figure 5d). The same does not occur in the synthetic experiments (Figure 3b) as the simulated data are representative of a soil layer between 0 and $30 \mathrm{~cm}$ for the VAL site. Notwithstanding all these issues, SM2RAIN is found to be able to capture the temporal variability of daily rainfall reasonably well both in the calibration and in the validation periods with only a slight degradation of the performance in validation period (see Figure 4).

By analysing the effect of the climate, we find that the performance increases from semiarid to humid temperate climates with average R-values varying from 0.84 to 0.90 . Similarly, higher R-values are found for sensors at depths of $\sim 15 \mathrm{~cm}$, or installed vertically, confirming the expected behaviour underlined in the examples of Figure 5. Indeed, one of the best results is found at the RES site for which the sensor is installed vertically $(0-30 \mathrm{~cm})$ thus allowing to measure the soil moisture variations for the entire first $30 \mathrm{~cm}$ of the soil layer. However, it should be noted that the relatively small number of sites analysed in this study does not allow us to draw general conclusions and a further study will specifically aim to address these aspects by considering a larger dataset (e.g., by taking the data from USA available for free at the International Soil Moisture Network (Dorigo et al., 2011)).

Besides model performance, it is interesting to analyse the results obtained from the different algorithm formulations (Equations 6-9). As shown in Figure 4, variations in the performance scores are very small and all configurations perform very similar. The only differences are found in the application of Equation (7), which neglects only the evapotranspiration term, for the ING, PET and K10 sites. These variations are mainly linked to a different value of the exponent $c$ of the surface runoff term (see Table 3 ) to which the algorithm is highly sensitive when Equation (7) is considered. However, the simulated rainfall with the different algorithms is very similar as already shown in the synthetic experiments. To further investigate this aspect, the contribution to the total simulated rainfall of each term of Equation (6) is computed by considering the whole data period. Figure 6 shows the time averaged contribution of each term for each site. As it can be seen, the major contribution is provided by the term incorporating the soil moisture variations, $Z^{*} d s(t) / d t$, with an average value of $63 \%$, followed by the drainage term $(30 \%)$. The evapotranspiration 
Rainfall estimation from in situ soil moisture observations at several sites in Europe: an evaluation of the SM2RAIN algorithm

Table 3. SM2RAIN parameter values for the different algorithm formulations ( $Z^{*}[\mathrm{~mm}]$ : soil water capacity; $a$ [mm/h]: coefficient of the drainage component; $b, c[-]$ : exponents of the drainage and the surface runoff components, respectively).

\begin{tabular}{c|cccc|cccc|ccc|ccc}
\hline \multirow{2}{*}{ Site ID } & \multicolumn{4}{|c|}{ Eq. (6) } & \multicolumn{4}{|c|}{ Eq. (7) } & \multicolumn{3}{|c}{ Eq. (8) } & \multicolumn{3}{c}{ Eq. (9) } \\
& $Z^{*}$ & $a$ & $b$ & $c$ & $Z^{*}$ & $a$ & $b$ & $c$ & $Z^{*}$ & $a$ & $b$ & $Z^{*}$ & $a$ & $b$ \\
\hline BAG & 64 & 19 & 7.2 & 40 & 64 & 18.8 & 7.1 & 39 & 65 & 22.6 & 7.7 & 67 & 21.7 & 7.6 \\
BIB & 63 & 0.7 & 9.9 & 40 & 65 & 0.8 & 11.5 & 40 & 62 & 1.2 & 12.4 & 65 & 1.2 & 12.6 \\
ING & 56 & 5.4 & 12.1 & 28 & 54 & 5.3 & 12.3 & 28 & 57 & 8.1 & 13.4 & 59 & 7.8 & 13.2 \\
K10 & 28 & 2.3 & 2 & 100 & 29 & 1.9 & 1.7 & 46 & 28 & 2.3 & 2 & 28 & 1.8 & 1.6 \\
M09 & 14 & 10.1 & 4 & 100 & 16 & 9.4 & 3.8 & 100 & 14 & 10.1 & 4 & 16 & 9.3 & 3.8 \\
PET & 44 & 0.8 & 4.3 & 7 & 53 & 2 & 5.2 & 38 & 51 & 1.4 & 4.6 & 52 & 1.3 & 4.4 \\
RES & 115 & 54.3 & 6.7 & 100 & 116 & 53.3 & 6.6 & 100 & 115 & 54.3 & 6.7 & 116 & 53.3 & 6.7 \\
SAL & 71 & 30.5 & 8.1 & 38 & 73 & 29.6 & 8 & 37 & 72 & 36.1 & 8.7 & 75 & 35.2 & 8.5 \\
TOR & 69 & 31 & 10 & 69 & 71 & 30.2 & 9.9 & 69 & 69 & 31 & 10 & 71 & 29.6 & 9.9 \\
VAL & 117 & 8.6 & 2.1 & 58 & 118 & 8.6 & 2.1 & 57 & 117 & 8.7 & 2.1 & 118 & 8.7 & 2.1 \\
\hline
\end{tabular}

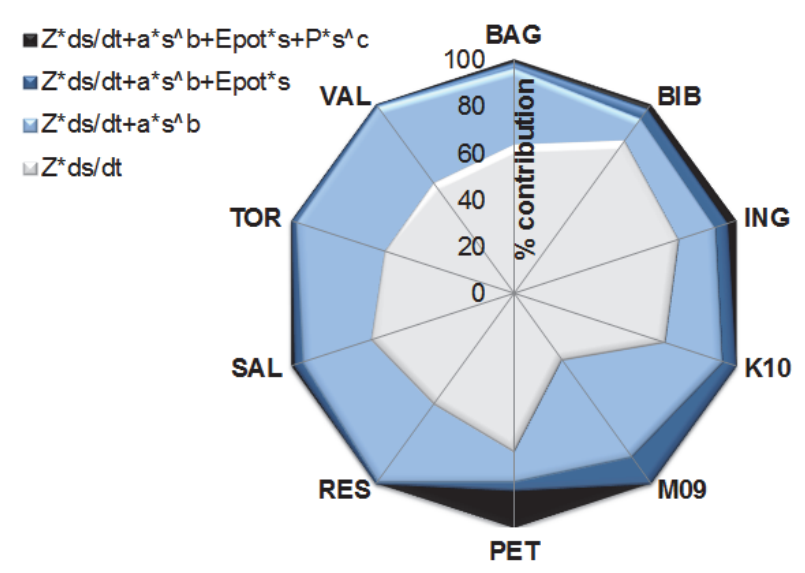

Fig. 6. Percentage contribution to the total simulated rainfall of the different terms in Equation (6): $Z^{*} d s(t) / d t=$ soil moisture variations, $a s(t)^{b}=$ deep percolation and subsurface runoff rate, $E_{p o t} s(t)=$ evapotranspiration rate, and $p(t) s(t)^{c}=$ surface runoff rate.

and the surface runoff components are negligible for all sites with an average combined contribution lower than $6 \%$. Only at the two Spanish sites (K10 and M09) the evapotranspiration component reaches a value higher than $7 \%$ while the surface runoff is relevant only at the PET site (16\%). These results explain why the evapotranspiration and the surface runoff components do not provide significant modification in the SM2RAIN algorithm performance and reliability.

Finally, also the model parameter values, shown in Table 3 , are found to be very similar among the different algorithm formulations. This highlights the simplicity of the proposed algorithm that allows one to obtain a robust rainfall estimates with no significant issues related to the identification of the model parameter values. As obtained in previous studies (Brocca et al., 2013), the parameters are also consistent with their expected physical values. The highest $Z^{*}$ value is obtained for the RES and VAL sites with sensors installed at a deeper soil layer $(30 \mathrm{~cm})$. The lowest values are observed for Spanish sites (K10 and M09) located close to the surface $(5 \mathrm{~cm})$ and characterized by a coarse soil texture. A similar behaviour can be also highlighted for $a$ and $b$ parameter values even though in this case the physical interpretation is more complex as these two parameters are not independent from each other. The lowest $c$ values are found for the two sites in central Italy (ING and PET) determining a larger contribution of surface runoff. This is expected and it can be ascertained by analysing the soil moisture time series that frequently reach values close to saturation (see Figure $5 b$ ).

\section{CONCLUSIONS}

An in depth investigation of the physical consistency and of the performance of the SM2RAIN algorithm in reproducing observed daily rainfall data is carried out by using synthetically generated data as well as high-quality in situ observations of rainfall, temperature and near-surface soil moisture for ten sites across Europe. Based on the obtained results, the following conclusions can be drawn:

1) For the synthetic experiments (Table 2 and Figure 3), the algorithm performance is found to be very high, thereby indicating that the simplified analytical equation of SM2RAIN allows to capture the dominant processes involved in the estimation of rainfall from soil moisture data.

2) For the real data experiments (Table 3 and Figures 4-5), the performance are found satisfactory both in the calibration and the validation periods (correlation values larger than 0.75 at all sites), with a consistency between the calibrated model parameter values and their expected physical values.

3) By analysing the results between the different sites (Figure 4), better performance is obtained for sites in humid temperate climates and for sensors installed vertically or horizontally at a depth of $\sim 15 \mathrm{~cm}$.

4) The most important result is that the surface runoff and evapotranspiration terms give a small contribution to the estimation of rainfall through SM2RAIN (Figure 6). Therefore, neglecting this does not deteriorate the algorithm performance (i.e., by considering Equation 6).

The reliability and accuracy demonstrated by the SM2RAIN algorithm in this study allows us to conclude that in situ soil moisture observations can be efficiently employed for providing an improvement in the estimation of rainfall. Indeed, even though classical measurement methods still represents point information, as those obtained by rain gauges, new approaches (e.g., Zreda et al., 2012) have been recently developed for providing area-integrated soil moisture measurements and, 
possibly, even rainfall estimates through the application of the SM2RAIN algorithm. Moreover, if considering satellite sensors data the potential of the SM2ARIN algorithm to improve rainfall estimates from state-of-the-art methods has been already demonstrated in previous studies (Brocca et al., 2014a; Ciabatta et al., 2015) and needs further investigations.

Future studies will be carried out to further improve the formulation of the SM2RAIN algorithm by considering the addition of a term for simulating the interception, the use of more accurate formulations for surface runoff estimation, the temporal variability of the parameter values (e.g., at monthly scale) and an improved methods for filtering noise from soil moisture measurements. For instance, for reducing the underestimation issue occurring at saturation, the integration of discharge data into the algorithm is foreseen by considering the method proposed by Kirchner (2009) or by Herrnegger et al. (2014). Moreover, the application of SM2RAIN to a large dataset will allow us to provide more robust indications on its applicability as a function of climate, soil texture, land use, and sensor installation type (depth and orientation).

Acknowledgements. The authors acknowledge the Micrometeorological Station team in Lecce of ISAC-CNR and the HyMeX database teams (ESPRI/IPSL and SEDOO/OMP), Sandra Perez from the Département de Géographie, Université de NiceSophia-Antipolis (France), and the International Soil Moisture Network (http://ismn.geo.tuwien.ac.at/), for supplying the data of Salento, Valescure, Bagnoli, Torano, and Ingegneria sites. The first author gratefully acknowledges support from the National Department of Civil Protection and Umbria Region. The Spanish participation in this work has been possible thanks to the support of the Spanish Ministry of Economy and Competitiveness (AYA2012-39356-C05-05 project). Support for running the Ressi site was provided by the project 'GEORISKS' (University of Padova, STPD08RWBY) and the project 'Giovani Studiosi-Ricerche di carattere innovative e di eccellenza proposte da giovani non strutturati. Patrick Matgen's time on this manuscript was supported by the National Research Fund of Luxembourg and the Belgian Science Policy through the HYDRAS+ project.

\section{REFERENCES}

Borga, M., 2002. Accuracy of radar rainfall estimates for streamflow simulation. J. Hydrol., 267, 1, 26-39.

Brocca, L., Hasenauer, S., Lacava, T., Melone, F., Moramarco, T., Wagner, W., Dorigo, W., Matgen, P., MartínezFernández, J., Llorens, P., Latron, J., Martin, C., Bittelli, M., 2011. Soil moisture estimation through ASCAT and AMSRE sensors: an intercomparison and validation study across Europe. Remote Sens. Environ., 115, 3390-3408.

Brocca, L., Ponziani, F., Moramarco, T., Melone, F., Berni, N., Wagner, W., 2012. Improving landslide forecasting using ASCAT-derived soil moisture data: A case study of the Torgiovannetto landslide in central Italy. Remote Sensing, 4, 5, 1232-1244.

Brocca, L., Melone, F., Moramarco, T., Wagner, W., 2013. A new method for rainfall estimation through soil moisture observations. Geophys. Res. Lett., 40, 5, 853-858.

Brocca, L., Ciabatta, L., Massari, C., Moramarco, T., Hahn, S., Hasenauer, S., Kidd, R., Dorigo, W., Wagner, W., Levizzani, V., 2014a. Soil as a natural rain gauge: estimating global rainfall from satellite soil moisture data. J. Geophys. Res. Atmos., 119, 9, 5128-5141.
Brocca, L., Camici, S., Melone, F., Moramarco, T., MartinezFernandez, J., Didon-Lescot, J.-F., Morbidelli, R., 2014 b. Improving the representation of soil moisture by using a semi-analytical infiltration model. Hydrol. Process., 28, 4, 2103-2115.

Brocca, L., Ciabatta, L., Massari, C., Moramarco, T., Hahn, S., Hasenauer, S., Kidd, R., Dorigo, W., Wagner, W., Levizzani, V., 2014c. Estimating rainfall from global satellite soil moisture data: recent improvements and applications. Poster presented at "Satellite soil moisture validation \& application workshop", Amsterdam, the Netherlands, 10-11 July 2014.

Ciabatta, L., Brocca, L., Moramarco, T., Wagner, W., 2015. Comparison of different satellite rainfall products over the Italian territory. Engineering Geology for Society and Territory, 3, 623-626.

Chen, F., Crow, W.T., Holmes, T.H., 2012. Improving longterm, retrospective precipitation datasets using satellite-based surface soil moisture retrievals and the soil moisture analysis rainfall tool. J. Appl. Remote Sens., 6, 1, 063604.

Chen, F., Crow, W.T., Ryu, D., 2014. Dual Forcing and State Correction via Soil Moisture Assimilation for Improved Rainfall-Runoff Modeling. J. Hydrometeor., 15, 1832-1848.

Corradini, C., Melone, F., Smith, R.E., 1997. A unified model for infiltration and redistribution during complex rainfall patterns. J. Hydrol., 192, 104-124.

Crow, W.T., Huffman, G.F., Bindlish, R., Jackson, T.J., 2009. Improving satellite rainfall accumulation estimates using spaceborne soil moisture retrievals. J. Hydrometeorol., 10, 199-212.

Crow, W.T., van Den Berg, M.J., Huffman, G.F., Pellarin, T., 2011. Correcting rainfall using satellite-based surface soil moisture retrievals: The Soil Moisture Analysis Rainfall Tool (SMART). Water Resour. Res., 47, W08521.

Doorenbos, J, Pruitt, W.O., 1977. Background and Development of Methods to Predict Reference Crop Evapotranspiration (ETo). Appendix II in FAO-ID-24, 108-119.

Dorigo, W.A., Wagner, W., Hohensinn, R., Hahn, S., Paulik, C., Drusch, M., Mecklenburg, S., Van Oevelen, P., Robock, A., and Jackson, T., 2011. The International Soil Moisture Network: a data hosting facility for global in situ soil moisture measurements, Hydrol. Earth Syst. Sci., 15, 1675-1698.

Draper, C., Reichle, R., de Jeu, R., Naeimi, V., Parinussa, R., Wagner, W., 2013. Estimating root mean square errors in remotely sensed soil moisture over continental scale domains. Remote Sens. Environ., 137, 288-298.

Ebert, E.E., Janowiak, J., Kidd, C., 2007. Comparison of near real time precipitation estimates from satellite observations and numerical models. Bull. Am. Meteorol. Soc., 88, 47-64.

Famiglietti, J.S., Wood, E.F., 1994. Multiscale modeling of spatially variable water and energy balance processes. Water Resour. Res., 11, 3061-3078.

Georgakakos KP, Baumer OW., 1996. Measurement and utilization of on-site soil moisture data. J. Hydrol., 184, 131-152.

Herrnegger, M., Nachtnebel, H.P., Schulz, K., 2014. From runoff to rainfall: inverse rainfall-runoff modelling in a high temporal resolution. Hydrol. Earth Syst. Sci. Discuss., 11, 13259-13309.

Hong, Y., Adler, R.F., Huffman, G.J., 2007. An experimental global prediction system for rainfall triggered landslides using satellite remote sensing and geospatial datasets. IEEE Trans. Geosci. Remote Sens., 45, 1671-1680.

Hou, A.Y., Kakar, R.K., Neeck, S., Azarbarzin, A.A., Kummerow, C.D., Kojima, M., Oki, R., Nakamura, K., Iguchi, T., 2014. The Global Precipitation Measurement (GPM) mission. Bull. Amer. Meteor. Soc., 95, 701-722. 
Kidd, C., Huffman, G., Kirschbaum, D., Skofronick-Jackson, G., Joe, P., Muller, C., 2014. So, how much of the Earth's surface is covered by rain gauges? Geophysical Research Abstracts, 16, EGU2014-10300.

Kirchner, J.W., 2009. Catchments as simple dynamical systems: catchment characterization, rainfall-runoff modeling, and doing hydrology backward. Water Resour. Res., 45, W02429.

Krier, R., Matgen, P., Görgen, K., Pfister, L., Hoffmann, L., et al., 2012. Inferring catchment precipitation by doing hydrology backwards: a test in 24 small and mesoscale catchments in Luxembourg. Water Resour. Res., 48, W10525.

Kucera, P.A., Ebert, E.E, Turk, F.J., Levizzani, V., Kirschbaum, D., Tapiador, F.J., Loew, A., Borsche, M., 2013. Precipitation from space: Advancing earth system science. Bull. Amer. Meteor. Soc., 94, 365-375.

Martinez-Fernandez, J., Ceballos, A., 2005. Mean soil moisture estimation using temporal stability analysis. J. Hydrol., 312, $1-4,28-38$.

Massari, C., Brocca, L., Moramarco, T., Tramblay, Y., Didon Lescot, J.-F., 2014. Potential of soil moisture observations in flood modelling: estimating initial conditions and correcting rainfall. Advances in Water Resources, 74, 44-53.

Matgen, P., Heitz, S., Hasenauer, S., Hissler, C., Brocca, L., Hoffmann, L., Wagner, W., Savenije, H.H.G., 2012. On the potential of METOP ASCAT-derived soil wetness indices as a new aperture for hydrological monitoring and prediction: a field evaluation over Luxembourg. Hydrol. Process., 26, 2346-2359.

Melone, F., Corradini, C., Morbidelli, R., Saltalippi, C., Flammini, A., 2008. Comparison of theoretical and experimental soil moisture profiles under complex rainfall patterns. Journal of Hydrologic Engineering, 13, 1170-1176.

Morbidelli, R., Corradini, C., Saltalippi, C., Flammini, A., Rossi, E., 2011. Infiltration-soil moisture redistribution under natural conditions: experimental evidence as a guideline for realizing simulation models. Hydrol. Earth Syst. Sci., 15, 2937-2945.
Pellarin, T., Louvet, S., Gruhier, C., Quantin, G., Legout, C., 2013. A simple and effective method for correcting soil moisture and precipitation estimates using AMSR-E measurements. Remote Sens. Environ., 136, 28-36.

Penna, D., van Meerveld, I., Oliviero, O., Zuecco, G., Assendelft, R.S., Dalla Fontana, G., Borga, M., 2014. Seasonal changes in run-off generation in a small forested mountain catchment. Hydrol. Process., doi: 10.1002/hyp.10347. (In press.)

Ramarohetra, J., Sultan, B., Baron, C., Gaiser, T., Gosset, M., 2013. How satellite rainfall estimate errors may impact rainfed cereal yield simulation in West Africa. Agricultural and Forest Meteorology, 180, 118-131.

Tian, Y., Liu, Y., Arsenault, K.R., Behrangi, A., 2014. A new approach to satellite-based estimation of precipitation over snow cover. International Journal of Remote Sensing, 35, 13, 4940-4951.

Tramblay, Y., Bouvier, C., Martin, C., Didon-Lescot, J.F., Todorovik, D., Domergue, J.M., 2010. Assessment of initial soil moisture conditions for event-based rainfallrunoff modelling. J. Hydrol., 387, 3-4, 176-187.

Tuttle, S.E., Salvucci, G.D., 2014. A new approach for validating satellite estimates of soil moisture using largescale precipitation: Comparing AMSR-E products. Remote Sens. Environ., 142, 207-222.

Villarini, G., Krajewski, W.F., 2010. Sensitivity studies of the models of radar-rainfall uncertainties. J. Appl. Meteor. Climatol., 49, 288-309.

Wake, B., 2013. Flooding costs. Nature Climate Change, 3, 778.

Zreda, M., Shuttleworth, W.J., Zeng, X., Zweck, C., Desilets, D., Franz, T., Rosolem, R., 2012. COSMOS: The COsmicray Soil Moisture Observing System. Hydrol. Earth Syst. Sci., 16, 4079-4099.

Received 8 November 2014 Accepted 13 January 2015

Note: Colour version of Figures can be found in the web version of this article. 